\title{
Superior Semicircular Canal
}

National Cancer Institute

\section{Source}

National Cancer Institute. Superior Semicircular Canal. NCI Thesaurus. Code C33695.

One of the three semicircular canals found in the osseous labyrinth of the inner ear, which detects rotation of the head around a rostral-caudal (anterior-posterior) axis. 